\title{
PERDA AUDITIVA HEREDITÁRIA: RELATO DE CASOS
}

\section{Hereditary hearing loss: case report}

\author{
Aline Mizozoe de Amorim (1), Carolina Alves Ferreira de Carvalho (2), \\ Marisa Frasson de Azevedo ${ }^{(3)}$, Silvia Bragagnolo Longhitano ${ }^{(4)}$
}

\begin{abstract}
RESUMO
Objetivo: descrever os resultados da avaliação auditiva de uma família com perda auditiva de caráter hereditário autossômico dominante. Métodos: foram avaliados 17 indivíduos, por meio da audiometria tonal, audiometria vocal, timpanometria e pesquisa dos reflexos acústicos, além de acompanhamento genético. Resultados: Dos 17 sujeitos avaliados, 11 apresentaram algum grau de perda auditiva neurossensorial (64,7\%), sendo oito do sexo feminino (73\%) e três do sexo masculino (27\%). A idade dos sujeitos avaliados variou de cinco a 68 anos (média=29,6) e a idade do aparecimento da queixa variou de 20 a 38 anos (média=26,1). Ocorreu a progressão da perda auditiva com o aumento da idade, sendo que a partir dos 41 anos, não houve indivíduos com audição normal na família. Conclusão: a investigação audiológica de todos os membros da família, independentemente da queixa, é imprescindível, pois a perda auditiva pode existir, mesmo que esta ocorra em freqüências isoladas.
\end{abstract}

DESCRITORES: Estudos de Casos; Perda Auditiva; Genética; Hereditariedade

\section{INTRODUÇÂO}

A perda auditiva pode ser causada tanto por fatores ambientais como fatores genéticos, podendo ocorrer em 1-3 de cada 1000 nascidos vivos ${ }^{1}$. O estudo da surdez de origem genética possibilita diagnósticos cada vez mais amplos, logo pacientes com causa indefinida de perda auditiva podem apresentar alterações genéticas determinantes de sua patologia ${ }^{2}$. A literatura refere que a hereditariedade, é responsável por grande parte das perdas auditivas bilaterais severas e/ou profundas ${ }^{3}$.

As desordens genéticas que provocam perda auditiva podem apresentar-se associadas a anoma-

(1) Fonoaudióloga; Especialização em Distúrbios da Comunicação Humana pela Universidade Federal de São Paulo.

(2) Fonoaudióloga; Mestranda em Distúrbios da Comunicação Humana pela Universidade Federal de São Paulo.

(3) Fonoaudióloga; Professora Adjunta do Curso de Fonoaudiologia da Universidade Federal de São Paulo; Doutora em Distúrbios da Comunicação Humana pela Universidade Federal de São Paulo.

(4) Médica Geneticista contratada do Centro de Genética Médica da Universidade Federal de São Paulo; Coordenadora do Centro de Atenção Integral à Saúde da Associação de Pais e Amigos dos Excepcionais de São Paulo; Mestre em Genética pelo Departamento de Morfologia da Universidade Federal de São Paulo. lias de outros órgãos (perda auditiva sindrômica) ou de forma isolada, sendo esta, a maioria encontrada na literatura ${ }^{4-6}$. Podem ser congênita, quando sintomática desde o nascimento, ou tardia, quando manifestada em qualquer idade após o nascimento ${ }^{7}$.

A perda auditiva hereditária, seja como uma manifestação de uma determinada síndrome ou sem qualquer outra anomalia associada, é, na maioria das vezes, regida pelas leis mendelianas de hereditariedade ${ }^{7,8}$. Se um gene anormal for suficiente para produzir uma deficiência auditiva, a perda é hereditária e caracterizada por um traço dominante. Se um par de genes anormal (um de cada genitor) for necessário para produzir a alteração, a deficiência é caracterizada por uma herança recessiva ${ }^{9}$. A perda auditiva genética não-sindrômica é classificada em autossômica dominante, autossômica recessiva, ligada ao cromossomo $\mathrm{X}$ ou de herança mitocondrial. Na transmissão de uma perda auditiva hereditária dominante, um dos pais, em geral, é afetado (com comprometimento auditivo), e transmite a anormalidade para cerca de $50 \%$ de seus filhos. $\mathrm{Na}$ transmissão recessiva, ambos os pais são portadores do gene, porém geralmente não são afetados (audição normal), e passam a perda auditiva para aproximadamente $25 \%$ dos seus filhos ${ }^{9}$.

Em geral, em termos fenotípicos, as formas autossômicas recessivas são mais graves, pré ou 
pós linguais. Na maioria das vezes são devidas a defeitos cocleares. Formas autossômicas dominantes parecem contribuir de forma mais expressiva para casos de surdez pós-lingual. Essas últimas são geralmente progressivas, menos graves, (pelo menos nos anos iniciais de aparecimento) e podem mostrar associação de déficits tanto condutivos quanto neurossensoriais ${ }^{10,11}$. Com a realização de exames para a investigação das mutações mais comuns associadas às perdas auditivas, tornouse possível o esclarecimento etiológico de alguns casos. A maioria das perdas auditivas de caráter genético não associadas a outras anormalidades (isoladas) possui padrão de herança autossômica recessiva, sendo que aproximadamente $50 \%$ de todos os tipos de perda de origem autossômica recessiva são deficiências isoladas ${ }^{7}$.

Foi realizado um estudo com 228 pacientes portadores de perda auditiva de causa genética comprovada ou suspeita no Ambulatório da Disciplina de Genética do Departamento de Morfologia da Universidade Federal de São Paulo no intuito de definir o diagnóstico genético-clínico e etiológico de cada caso. Os pacientes foram divididos em 2 grupos, conforme sua casuística: o grupo retrospectivo, composto por 140 indivíduos pertencentes a 113 famílias e o grupo prospectivo, constituído por 88 indivíduos pertencentes a 75 famílias. Analisandose as duas casuísticas como um todo, os casos de perda auditiva isolada predominaram sobre os sindrômicos, com 59,6\% do total (112 famílias em 188). Quanto ao padrão de herança $49,9 \%$ entre sindrômicos e não-sindrômicos foram de herança autossômica recessiva e 10,6\% foram de herança autossômica dominante ${ }^{12}$.

A perda auditiva hereditária também pode ser do tipo condutiva ou mista, mas na maioria dos casos é do tipo neurossensorial. Isto significa que genes anômalos são, muitas vezes, responsáveis por alterações estruturais ou fisiopatológicas das células da orelha interna ou por degeneração de suas estruturas. Perda auditiva hereditária e congênita freqüentemente são vistas como sinônimas, mas nem sempre o são. A perda auditiva congênita está presente ao nascimento, mas não necessariamente é hereditária, podendo ser decorrente de outras causas (infecções maternas). Por outro lado, existem casos de deficiência auditiva hereditária que se manifestam tardiamente na vida dos indivíduos ${ }^{13}$.

A classificação da perda auditiva neurossensorial hereditária é baseada tanto em características genéticas, etiológicas, como histopatológicas. Estudos do osso temporal em pacientes com perda auditiva neurossensorial hereditária, podem mostrar ausência do órgão espiral, degeneração do gânglio espiral e degeneração irregular da estria vascular ${ }^{14}$.
Desta forma o objetivo deste trabalho é descrever os resultados da avaliação audiológica de uma família com perda auditiva de caráter hereditário autossômico dominante.

\section{MÉTODOS}

Este estudo foi realizado no Ambulatório da disciplina de Distúrbios da Audição da Universidade Federal de São Paulo - Escola Paulista de Medicina, no decorrer do ano de 2005.

Os participantes deste estudo pertencem a uma família constituída por 21 indivíduos, cuja representação gráfica da genealogia corresponde a Figura 1. Os algarismos romanos I, II, III e IV à esquerda da genealogia representam as gerações e os algarismos arábicos indicam os indivíduos de cada geração.

Foram submetidos à avaliação audiológica 17 indivíduos (cinco anos a 68 anos, idade média $=$ 29,6). Dentre os participantes apenas a mãe, seus cinco filhos e um neto apresentavam queixas sugestivas de rebaixamento auditivo. Os dados referentes aos indivíduos constituintes desta família encontram-se descritos na Tabela 1, organizados segundo o grau de parentesco, sexo, idade e atividade profissional. Cabe ressaltar que os indivíduos II-3, II-6 e III-3 (cônjuges) não participaram do estudo, tendo sido representados na Figura 1 para facilitar a compreensão dos dados.

Para seleção da amostra foram adotados os seguintes critérios de inclusão: 1. Grau de parentesco com a matriarca da família; 2 . Ausência de queixas relacionadas a distúrbios neurológicos, comportamentais ou cognitivos, 3. Presença de curva timpanométrica tipo A bilateralmente.

Inicialmente, os participantes foram submetidos a avaliações realizadas pelo Centro de Genética Médica da UNIFESP - EPM, por meio da propedêutica genético-clínica, que envolveu: 1 . Realização de anamnese com investigação detalhada da história pessoal e familiar, 2. Realização de exames físico geral e específico com antropometria detalhada e solicitação de exames subsidiários necessários, 3. Construção de heredograma.

Posteriormente, os participantes foram encaminhados para avaliação audiológica que consistiu em anamnese, na qual foram colhidas informações específicas sobre a audição, seguida da avaliação audiológica convencional composta pelos seguintes exames: audiometria tonal liminar, audiometria vocal, timpanometria e pesquisa dos reflexos acústicos. As medidas desta pesquisa foram obtidas em cabina tratada acusticamente, utilizando um audiômetro de um canal da marca Maico MA - 41, cuja calibração obedece ao padrão proposto pela Ame- 
I

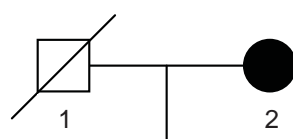

II

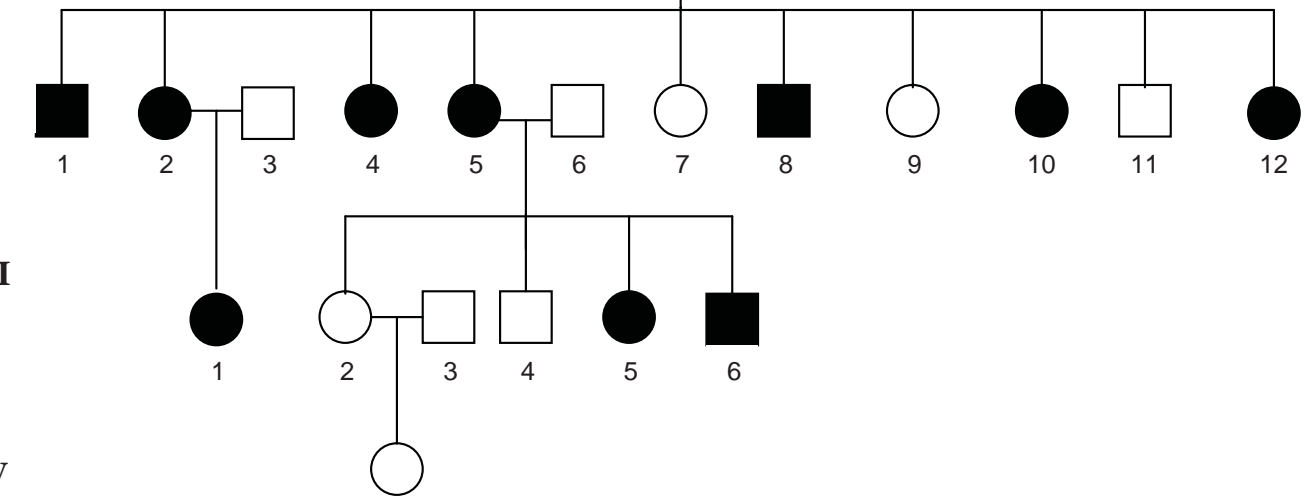

IV

1

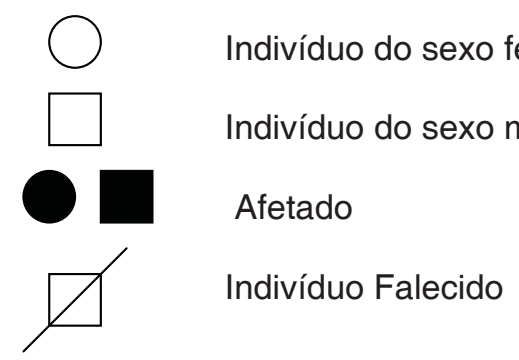

Figura 1 - Heredograma

Tabela 1 - Indivíduos da família, segundo grau de parentesco, sexo, idade e profissão

\begin{tabular}{|c|c|c|c|c|c|}
\hline Sujeito & Grau de parentesco & Sexo & Idade & Profissão & $\begin{array}{c}\text { Idade do } \\
\text { aparecimento da } \\
\text { queixa auditiva }\end{array}$ \\
\hline $\mid-1$ & Pai (falecido) & masculino & ----- & |--------------- & --------- \\
\hline I-2 & Mãe & feminino & 68 & do lar & 21 \\
\hline$\|-1$ & Filho & masculino & 44 & arquiteto & 20 \\
\hline II-2 & Filha & feminino & 43 & escriturária & 38 \\
\hline II-4 & Filha & feminino & 39 & do lar & 31 \\
\hline II-5 & Filha & feminino & 38 & do lar & 28 \\
\hline II-7 & Filha & feminino & 37 & do lar & sem queixa \\
\hline II-8 & Filho & masculino & 36 & gerente de marketing & sem queixa \\
\hline II-9 & Filha & feminino & 31 & enfermeira & sem queixa \\
\hline II-10 & Filha & feminino & 30 & operadora de seguros & 25 \\
\hline II-11 & Filho & masculino & 28 & segurança & sem queixa \\
\hline II-12 & Filha & feminino & 26 & secretária & sem queixa \\
\hline III-1 & Neta & feminino & 22 & estudante & 20 \\
\hline III-2 & Neta & feminino & 17 & estudante & sem queixa \\
\hline III-4 & Neto & masculino & 15 & estudante & sem queixa \\
\hline III-5 & Neta & feminino & 14 & estudante & sem queixa \\
\hline III-6 & Neto & masculino & 11 & estudante & sem queixa \\
\hline IV-1 & Bisneta & feminino & 05 & estudante & sem queixa \\
\hline
\end{tabular}


rican National Institute (ANSI - 69), fones TDH 39 e coxim $M X-41$. As medidas de imitância acústica foram realizadas utilizando o analisador de orelha média INTERACOUSTICS AZ-7.

Os critérios utilizados para a consideração de normalidade audiológica foram:

- Meatoscopia revelando ausência de qualquer componente obstrutivo do meato acústico externo;

- Limiar de audibilidade para tom puro de 0 a 25 dB NA em todas as freqüências testadas $(250 \mathrm{~Hz}$, $500 \mathrm{~Hz}, 1000 \mathrm{~Hz}, 2000 \mathrm{~Hz}, 3000 \mathrm{~Hz}, 4000 \mathrm{~Hz}$, $6000 \mathrm{~Hz}$ e $8000 \mathrm{~Hz}$ ) na audiometria tonal liminar. O critério utilizado para a classificação referente ao grau da perda auditiva foi: Normal (0-25 dB), Leve (21-40 dB), Moderada (41-70 dB), Severa (71-90 dB) e Profunda (acima de $95 \mathrm{~dB}$ ) ${ }^{15}$.

- Valor em porcentagem de 90 a 100\% no índice percentual de reconhecimento de fala;

- Pico de máxima compliância ao redor da pressão atmosférica de 0 a -150 daPa, o volume equivalente de 0,3 a 1,3 $\mathrm{ml}$ e reflexo acústico de 70 a $90 \mathrm{~dB}$ acima do limiar de audibilidade para tom puro ${ }^{16}$.

Os resultados obtidos nas avaliações auditivas e genético-clínicas da família em questão são apresentados de forma descritiva e discutidos comparativamente.

Esta pesquisa foi previamente aprovada pelo Comitê de Ética em Pesquisa da UNIFESP (no 0554/05) e tendo início após a autorização dos participantes ou seus responsáveis, por meio da assinatura dos Termos de Consentimento Livre e Esclarecido.

\section{RESULTADOS}

Dos 17 indivíduos avaliados, 11 apresentaram algum grau de perda auditiva neurossensorial $(64,7 \%)$, conforme observa-se a seguir (Indivíduos I-2, II-1, II-2, II-4, II-5, II-8, II-10, II-12, III-1, III-5, III-6 representados nas Figuras 2, 3, 4, 5, 6, 7, 8, $9,10,11,12$, respectivamente), sendo oito do sexo feminino $(73 \%)$ e três do sexo masculino $(27 \%)$. A idade dos indivíduos sujeitos avaliados variou de cinco a 68 anos de idade (média $=29,6$ ) e a idade do aparecimento da queixa variou de 20 a 38 anos (média=26,1) (Tabela 1).

O pai dos sujeitos avaliados (Sujeito I-1) faleceu aos 50 anos de idade de causa ignorada. Os parentes informaram que o mesmo apresentava boa audição antes de falecer, mas não souberam informar se havia antecedentes de perda auditiva em sua família.

Nas Tabelas 2 e 3, observa-se que seis sujeitos apresentaram audição normal (três na faixa etária 5-20 anos, um na de 21-30 anos e dois na de 31-40 anos). Dos 11 sujeitos com perda auditiva, três apresentaram perda auditiva em freqüências isoladas (dois na faixa etária 5-20 anos

Tabela 2 - Resultado da Audiometria Tonal Liminar em cada sujeito avaliado

\begin{tabular}{|c|c|}
\hline Sujeito & Resultado da Audiometria \\
\hline $\mathrm{I}-2$ & Perda Auditiva de grau profundo Bilateral \\
\hline II-1 & Perda Auditiva de grau severo a profunda Bilateral \\
\hline II-2 & Perda Auditiva de grau leve a profundo Bilateral \\
\hline II-4 & Perda Auditiva de grau moderado a profundo Bilateral \\
\hline II-5 & Perda Auditiva de grau leve a profundo Bilateral \\
\hline II-7 & Normal \\
\hline II-8 & Perda Auditiva de grau leve a moderado Bilateral \\
\hline II-7 & Normal \\
\hline II-10 & Perda Auditiva de grau leve a profundo Bilateral \\
\hline||$-11$ & Normal \\
\hline II-12 & $\begin{array}{l}\text { Perda Auditiva isolada de grau moderado nas freqüências de } 4,6 \text { e } 8 \mathrm{kHz} \\
\text { à orelha esquerda }\end{array}$ \\
\hline III-1 & Perda Auditiva de grau moderado a severo Bilateral \\
\hline III-2 & Normal \\
\hline III-4 & Normal \\
\hline III-5 & Perda Auditiva isolada de grau leve na freqüência de 6 kHz Bilateral \\
\hline III-6 & Perda Auditiva isolada de grau leve na freqüência de $6 \mathrm{kHz}$ à orelha esquerda \\
\hline IV-1 & Normal \\
\hline
\end{tabular}


Tabela 3 - Tipo e grau da perda auditiva (PA), segundo a idade

\begin{tabular}{|c|c|c|c|c|c|c|}
\hline Idade & $\begin{array}{c}\text { Audição } \\
\text { normal }\end{array}$ & $\begin{array}{l}\text { PA em } \\
\text { freqüências } \\
\text { isoladas }\end{array}$ & $\begin{array}{c}\text { PA } \\
\text { descendente } \\
\text { leve a } \\
\text { moderada }\end{array}$ & $\begin{array}{c}\text { PA } \\
\text { descendente } \\
\text { leve a } \\
\text { profunda }\end{array}$ & $\begin{array}{c}\text { PA } \\
\text { descendente } \\
\text { moderada a } \\
\text { profunda }\end{array}$ & $\begin{array}{c}\text { PA severa I } \\
\text { profunda }\end{array}$ \\
\hline $\begin{array}{l}5-20 \\
\text { anos }\end{array}$ & 3 & 2 & 0 & 0 & 0 & 0 \\
\hline $\begin{array}{l}21-30 \\
\text { anos }\end{array}$ & 1 & 1 & 0 & 1 & 1 & 0 \\
\hline $\begin{array}{l}31-40 \\
\text { anos }\end{array}$ & 2 & 0 & 1 & 1 & 1 & 0 \\
\hline $\begin{array}{l}\text { Acima } \\
\text { de } 40\end{array}$ & 0 & 0 & 0 & 1 & 0 & 2 \\
\hline Total & 6 & 3 & 1 & 3 & 2 & 2 \\
\hline
\end{tabular}

Tabela 4 - Sujeitos com Perda Auditiva com e sem queixa

\begin{tabular}{ccccccc}
\hline & $\begin{array}{c}\text { PA em } \\
\text { freqüencias } \\
\text { isoladas }\end{array}$ & $\begin{array}{c}\text { PA } \\
\text { descendente } \\
\text { leve a } \\
\text { moderada }\end{array}$ & $\begin{array}{c}\text { PA } \\
\text { descendente } \\
\text { leve a } \\
\text { profunda }\end{array}$ & $\begin{array}{c}\text { PA } \\
\text { descendente } \\
\text { moderada a } \\
\text { profunda }\end{array}$ & $\begin{array}{c}\text { PA severa } \\
\text { / profunda }\end{array}$ & Total \\
\hline $\begin{array}{c}\text { Sem } \\
\text { queixa } \\
\text { Com }\end{array}$ & 3 & 1 & 0 & 0 & 0 & 4 \\
queixa & 0 & 0 & 3 & 2 & 2 & 7 \\
\hline Total & 3 & 1 & 3 & 2 & 2 & 11 \\
\hline
\end{tabular}

e um na de 21 a 30 ); um apresentou perda auditiva descendente de grau leve a moderado (faixa etária 31-40 anos); três apresentaram perda auditiva descendente de grau leve a profundo (faixa etária 21 a 30 anos, 31 a 40 e acima de 40); dois apresentaram perda auditiva de grau moderado a severo/profundo (faixa etária 21 a 30 anos e 31 a 40) e dois apresentaram perda auditiva severa e/ou profunda (faixa etária acima de 40 anos). Pode-se observar que com o aumento da idade, ocorreu a progressão da perda auditiva, sendo que a partir de 41 anos não houve indivíduos com audição normal dentro da família (Figura 13).

Procurou-se verificar a relação entre a presença de queixa e o grau da perda auditiva (Tabela 4). Dos 11 sujeitos, quatro não apresentaram queixa auditiva, sendo que três apresentaram perda auditiva em freqüências isoladas e um apresentou perda auditiva descendente de grau leve a moderado. Nos sete que apresentaram queixa auditiva, o grau da perda era mais elevado.

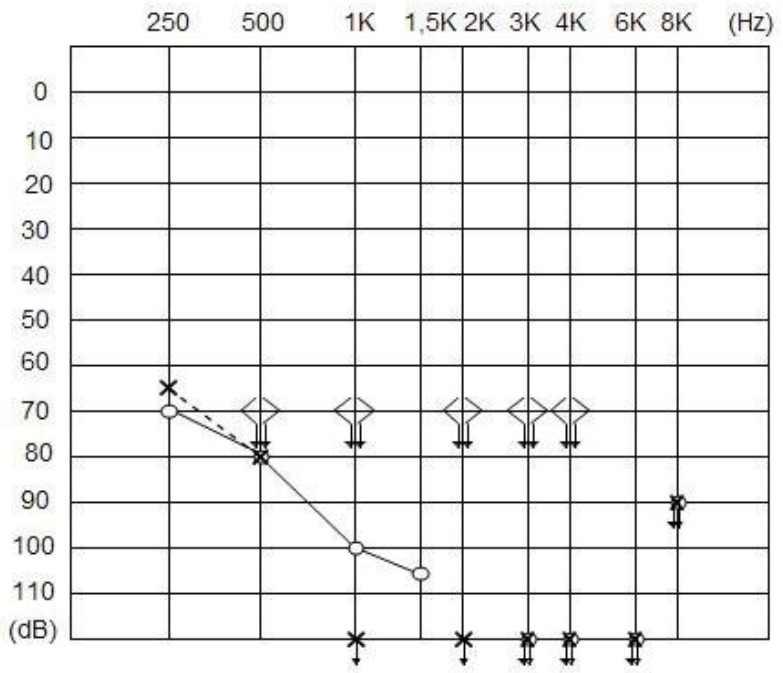

Figura 2 - Audiograma do Indivíduo I 2 


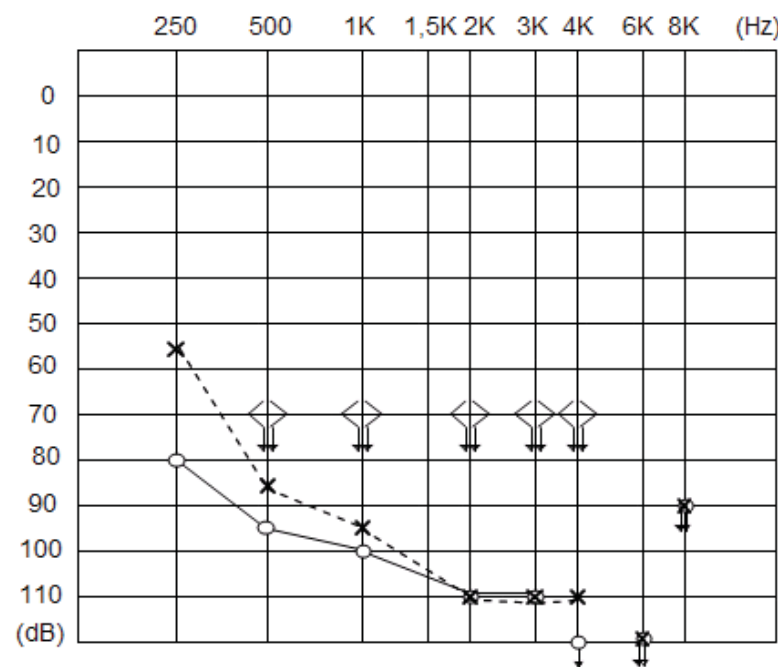

Figura 3 - Audiograma do Indivíduo II 1

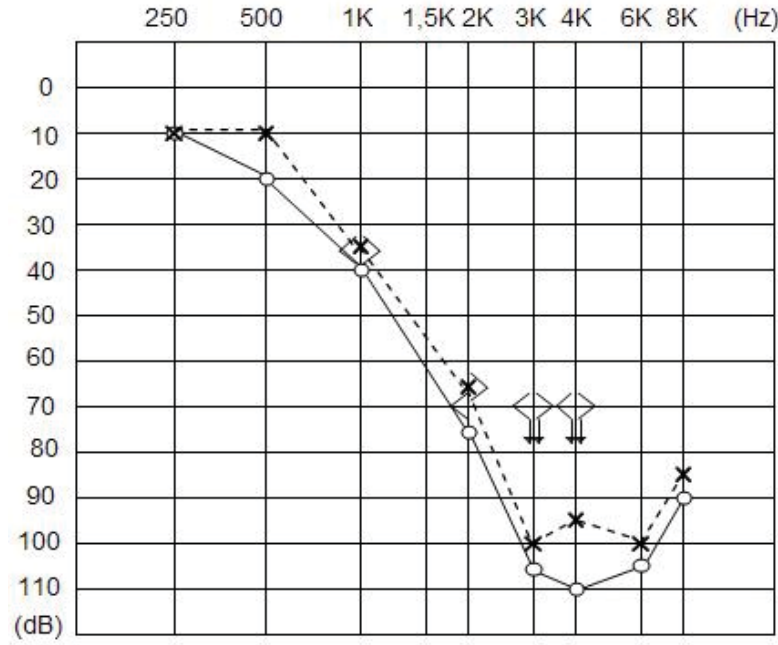

Figura 4 - Audiograma do Indivíduo II 2

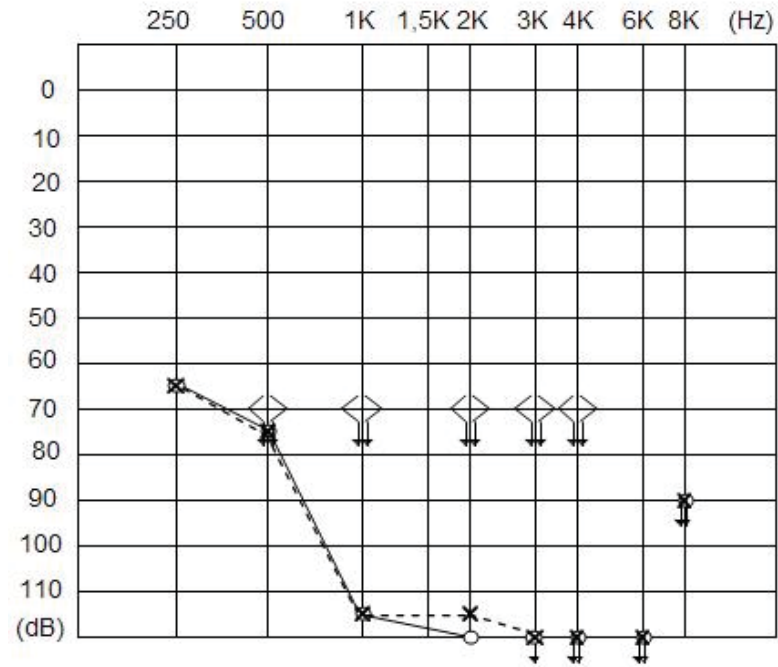

Figura 5 - Audiograma do Indivíduo II 4

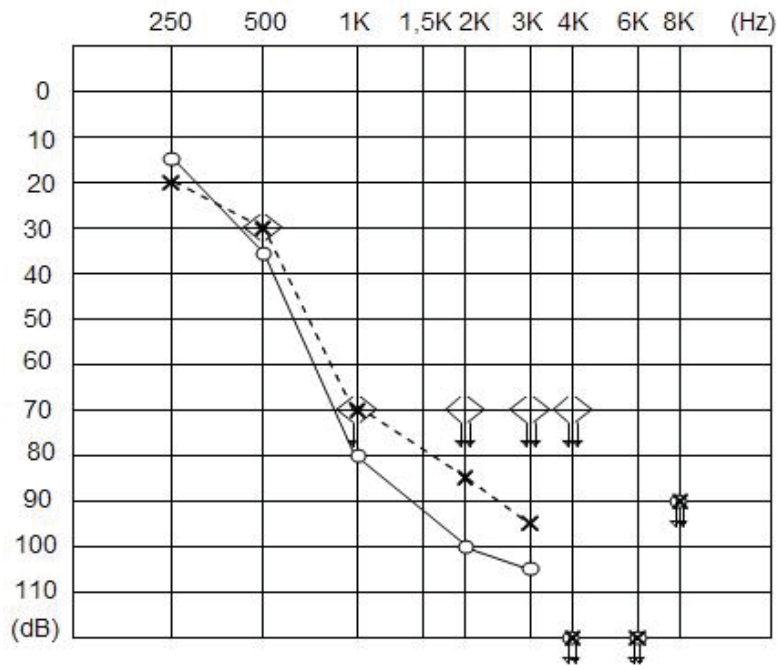

Figura 6 - Audiograma do Indivíduo II 5

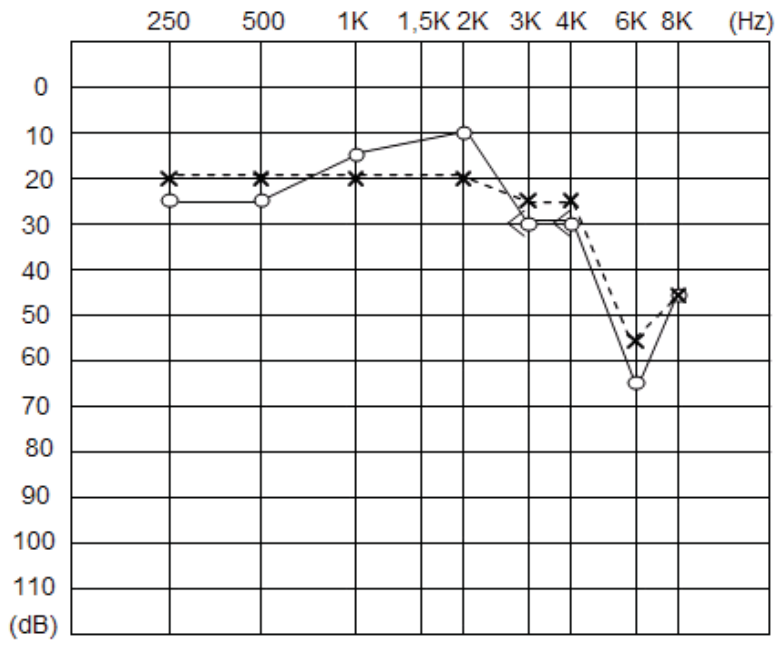

Figura 7 - Audiograma do Indivíduo II 8

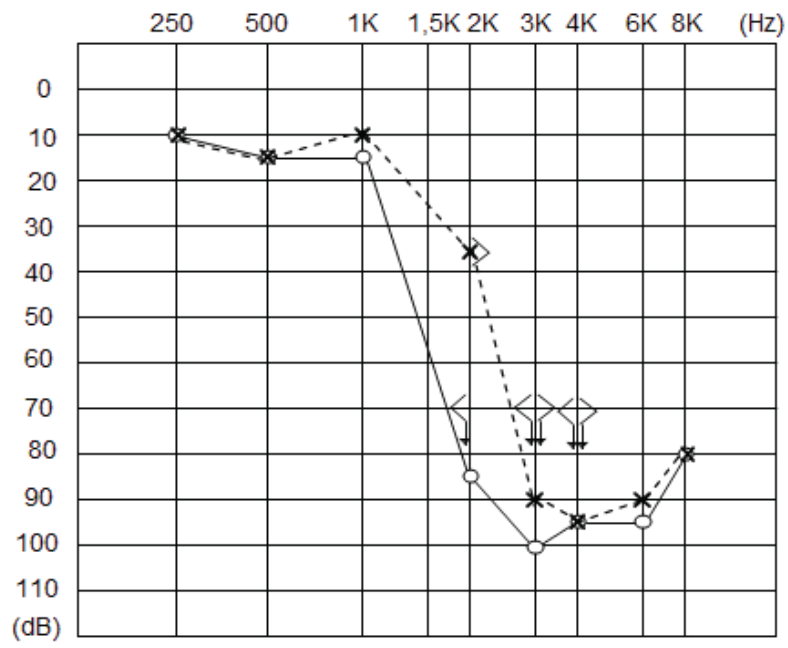

Figura 8 - Audiograma do Indivíduo II 10 


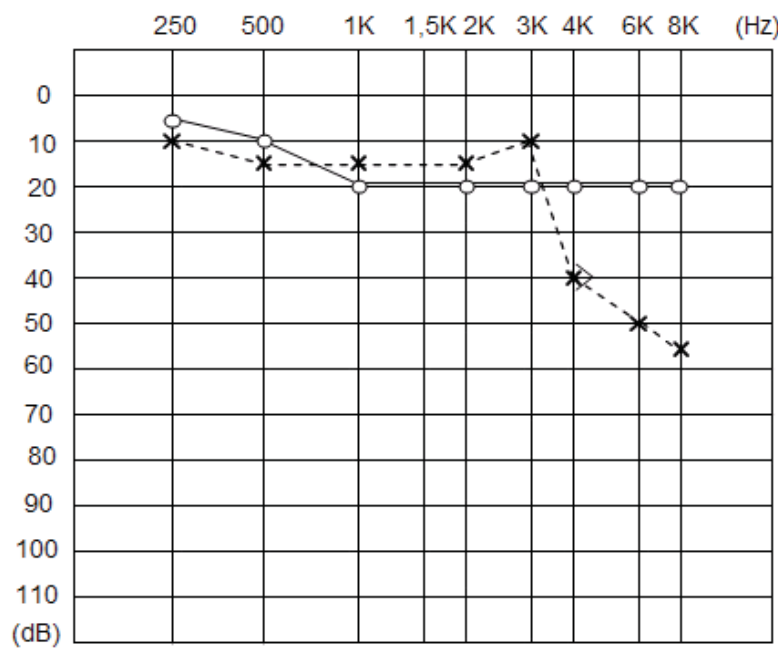

Figura 9 - Audiograma do Indivíduo II 12

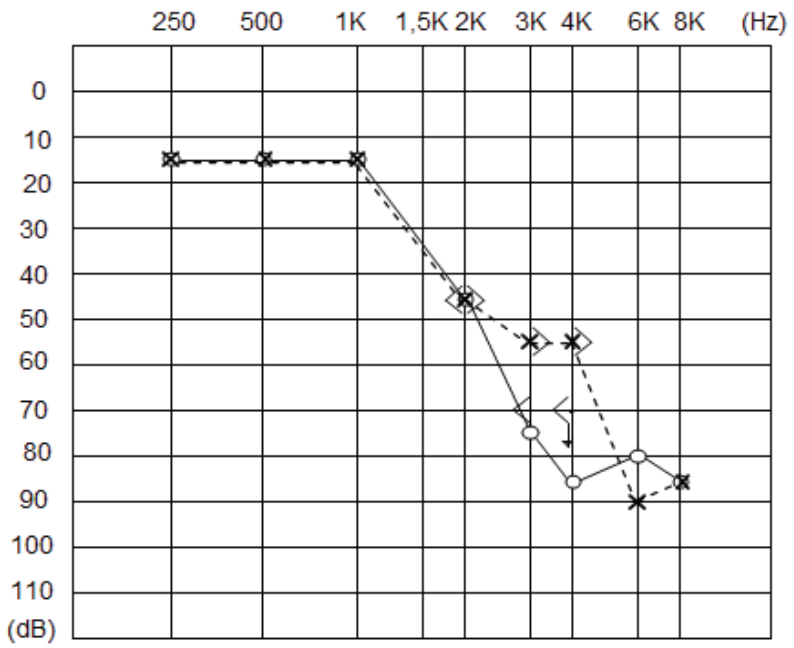

Figura 10 - Audiograma do Indivíduo III 1

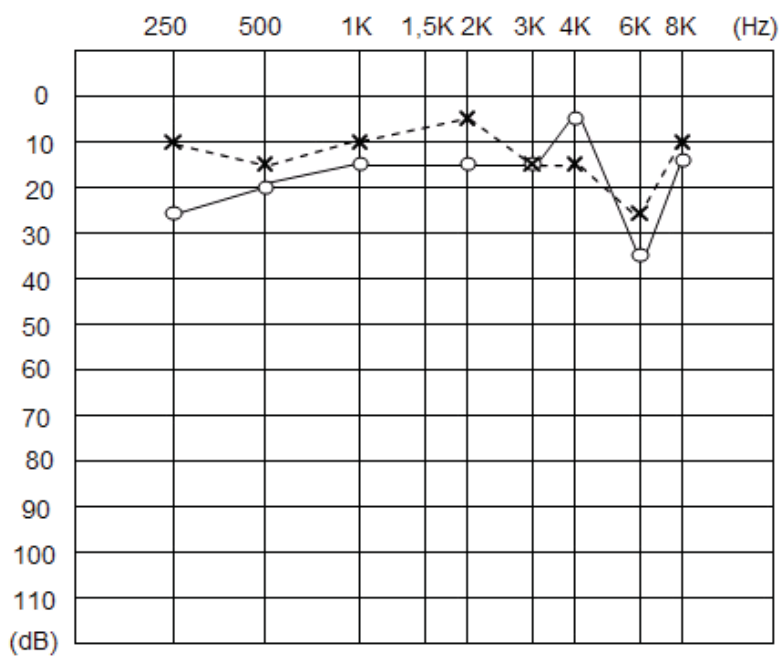

Figura 11 - Audiograma do Indivíduo III 5

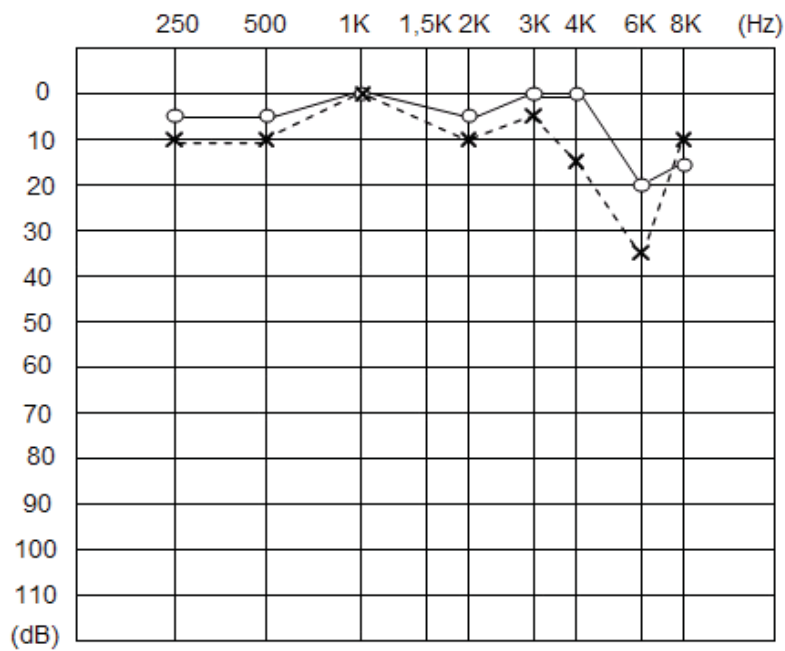

Figura 12 - Audiograma do Indivíduo III 6

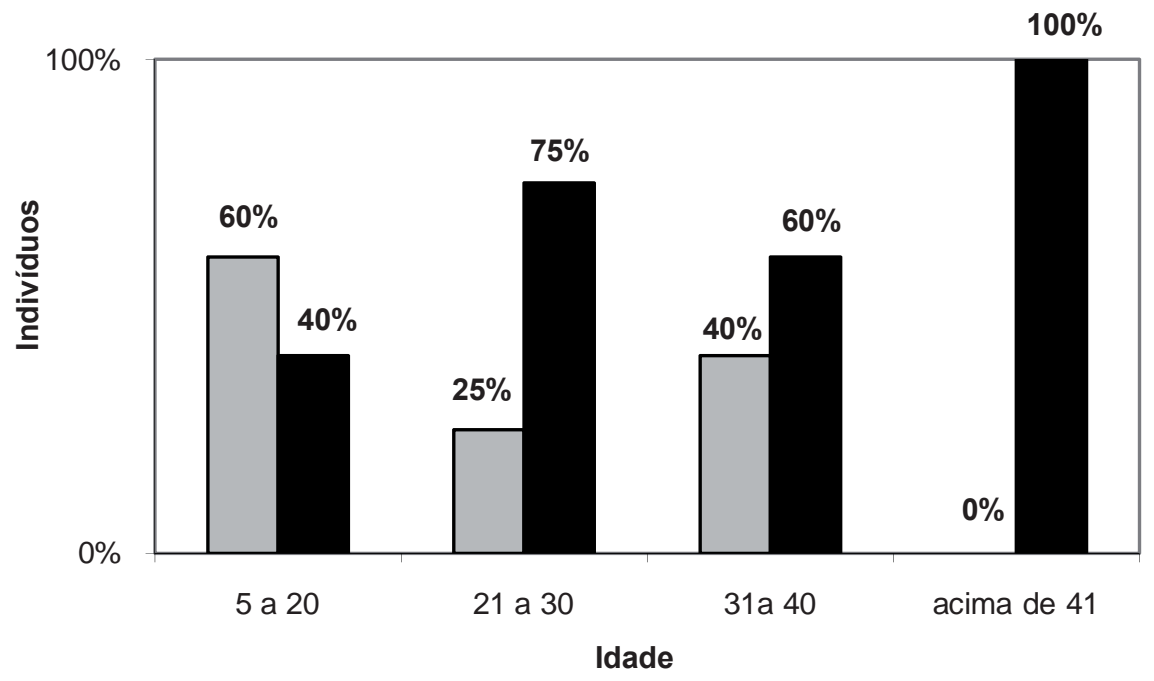

口Audição Normal

- Audição Alterada

Figura 13 - Ocorrência de perda auditiva, segundo a idade 


\section{DISCUSSÃO}

Considerando os dados apresentados, pode-se considerar a família estudada um exemplo clássico de perda auditiva hereditária. A hereditariedade, segundo a literatura especializada, é responsável por grande parte das perdas auditivas bilaterais severas e/ou profundas. Dentre os estudos sobre o tema, pode-se pontuar uma investigação realizada por pesquisadores espanhóis que buscaram investigar a etiologia das perdas auditivas bilaterais severas e/ou profundas de 100 pacientes atendidos em dois hospitais. Os autores concluíram que em aproximadamente $50 \%$ dos casos, a perda auditiva foi de origem hereditária ${ }^{3}$.

A avaliação genético-clínica da família em questão levou ao diagnóstico de perda auditiva isolada, por serem afastadas outras alterações que sugerissem um quadro sindrômico. A confecção do heredograma a partir da história familial demonstrou um padrão de herança autossômica dominante. $\mathrm{O}$ estudo da história pregressa da deficiência na família, associada ao padrão audiológico, levou ao diagnóstico de perda auditiva autossômica dominante progressiva ou, como descrita por outros autores, autossômica dominante neurossensorial precoce ${ }^{17}$. Os resultados do presente estudo estão em concordância com os dados da literatura ${ }^{2,4,5,7}$, indicando que a maioria das causas genéticas de surdez são não-sindrômicas. Entretanto, entre as causas não sindrômicas, tem sido observado na maior parte dos estudos o padrão de herança autossômico recessivo, o que difere da família analisada nesta pesquisa. Em um estudo realizado com crianças em um hospital na Grécia, foi verificado que de 94 crianças portadoras de perda auditiva, $47 \%$ eram de causa hereditária, sendo $23 \%$ do tipo sindrômica e $77 \%$ não-sindrômica (29\% padrão autossômico dominante e $48 \%$ padrão recessivo) ${ }^{6}$.

De acordo com a investigação clínica realizada e com a análise do heredograma da família estudada, verificou-se que três gerações (I, II e III) apresentaram indivíduos com perda auditiva, e que ambos os sexos foram afetados (11 dos 17 sujeitos avaliados). Além disso, foi verificado que houve uma piora na ocorrência de perda auditiva com o aumento da idade. Neste caso, a perda auditiva está inicialmente limitada a uma estreita faixa de freqüência, primeiramente as altas (sujeitos II-12, III-5 e III-6 com idades de 26, 14 e 11 anos respectivamente) e progride envolvendo também freqüências médias (sujeitos II-2, II-5, II-8, II-10 e III-1 com idades de $43,38,36,30$ e 22 respectivamente) até o acometimento de todas as freqüências (sujeitos I-2, II-1 e II-4, com idades de 68, 44, 39 respectivamente). Estes achados corroboram estudos, que demonstram que é característica do padrão de herança autossômica dominante a presença de perda auditiva progressiva com início na infância, acometimento das freqüências altas inicialmente $e$ com o aumento da idade, o acometimento de todas as freqüências ${ }^{4,9,17}$.

A idade que permitiu a percepção da dificuldade auditiva pelos indivíduos variou de 20 a 38 anos ( édia $=26,1$ ), sendo que dentre os afetados cinco não referiram queixa. Tal fato pode estar associado à configuração audiométrica da perda, na qual há a preservação das freqüências da fala e perda apenas em freqüências altas isoladas. A literatura refere que a discriminação da fala pode ser pouco comprometida em perdas auditivas neurossensoriais que atingem apenas freqüências mais altas (acima de $2000 \mathrm{~Hz}$ ), devido à área da fala concentrar energia na faixa de freqüências entre 400 e $4000 \mathrm{~Hz}$, embora inclua freqüências mais baixas (área da freqüência fundamental) e altas (formantes de algumas consoantes) ${ }^{18}$.

\section{CONCLUSÃO}

As avaliações auditivas e genético-clínicas permitiram concluir que a família estudada representa um exemplo clássico de perda auditiva neurossensorial isolada de herança autossômica dominante. A perda auditiva caracterizou-se como neurossensorial e progressiva com o aumento da idade. A idade média do aparecimento de queixas auditivas foi de 26,1 anos, sendo que a partir dos 40 anos de idade, todos os sujeitos pesquisados apresentavam perda auditiva neurossensorial. 


\section{ABSTRACT}

Purpose: to describe the hearing findings of a family with autosome dominant hereditary hearing loss. Methods: we evaluated 17 subjects. The evaluation was made by pure tone audiometry, Speech audiometry, tympanometry and acoustic reflex testing, in addition to genetic follow-up. Results: from 17 evaluated subjects, 11 showed some degree of neurosensorial hearing loss $(64.7 \%)$, being 8 female gender $(73 \%)$ and 3 male gender $(27 \%)$. The subject age varied from 5 to 68 years (average $=$ 39.6) and the time from the complaint's appearance varied from 20 to 38 years. The hearing loss was modified with age. We did not find normal hearing after the age of 41 years in the family. Conclusion: the hearing investigation regarding all members of the family regardless of any complaint is extremely indispensable due to the existence of hearing loss even when limited to isolated frequencies.

KEYWORDS: Case Studies; Hearing Loss; Genetics; Heredity

\section{REFERÊNCIAS}

1. Northern JL, Downs MP. Audição na infância. Rio de Janeiro: Guanabara Koogan; 2005. 359 p.

2. Pfeilsticker LN, Stole G, Sartorato EL, Delfino D, Guerra ATM. A investigação genética na surdez hereditária não-sindrômica. Rev Bras Otorrinolaringol. 2004; 70(2):182-6.

3. Morales-Angulo C, Gallo-Terán J, Azuara N, Quintela JR. Etiology of severe/profound, pre/perilingual bilateral hearing loss in Cantabria (Spain). Acta Otorrinolaringol Esp. 2004; 55(8):351-5.

4. Gorlin RJ, Toriello HV, Cohen NM. Hereditary hearing loss and Its syndromes. New York: Oxford University Press; 1995. 477 p.

5. Godinho R, Keogh I, Eavey R. Perda auditiva genética. Rev Bras Otorrinolaringol. 2003; 69(1):100-4.

6. Riga M, Psarommatis I, Lyra $\mathrm{CH}$, Douniadakis D, Tsakanikos M, Neou P, Apostolopoulos N. Etiological diagnosis of bilateral, sensorineural hearing impairment in a pediatric Greek population. Int J Pediatr Otorhinolaryngol. 2005; 69(4):449-55.

7. Granato L, Pinto CF, Ribeiro MQ. Perda auditiva de origem genética. In: Lopes Filho $\mathrm{O}$. Tratado de fonoaudiologia. São Paulo: Tecmedd; 2004. p. 41-68.

RECEBIDO EM: 6/12/2006

ACEITO EM: 06/02/2008

Endereço para correspondência:

Rua Ibituruna, 265, ap. 71-A

São Paulo - SP

CEP: 04102-051

Tel: (11) 82398184 / 55891204

E-mail: alikamorim@terra.com.br
8. Bess FH, Humes LE. Fundamentos de audiologia. Porto Alegre: Artmed; 1998. 326 p.

9. Jerger S, Jerger J. Alterações auditivas: um manual para avaliação clínica. São Paulo: Atheneu; 1998. p. 73-8.

10. Petit C. Genes responsible for human hereditary deafness: symphony of a thousand. Nat Genet. 1996; 14(4):385-91.

11. Van Camp G, Willems PJ, Smith RJ. Nonsyndromic hearing impairment: unparalleled heterogeneity. Am J Hum Genet. 1997; 60(4):758-64.

12. Longhitano SB, Brunoni D. Genetic hearing loss: a study of 228 Brazilian patients. Genet Mol Biol. 2000; 23(1):25-7.

13. Rugolo LMSS, Saes SO, Camargo LOS, Paro PMM. Fatores de risco para a audição na infância. Bauru: EDUSC; 2002. 57 p.

14. Paparella M, Capps M. Sensori-neural deafness in children genetic. In: Paparella M, Shumrick D. Otolaryngology. Philadelphia: Saunders; 1973. p. 320-37.

15. Jeger J. Clinical experience with impedance audiometry. Arch Otolaryngol. 1970; 92(4):311-24.

16. Davis H, Silverman SR. Auditory test hearing Aids. In: Davis H, Silverman SR. Hearing and deafness. Holt: Rinehart and Winston; 1970. p. 253-79.

17. Konigsmark BW, Gorlin RJ. Genetic and metabolic deafness. Philadelphia: W.B. Saunders; 1976. $419 \mathrm{p}$.

18. Russo ICP. Noções básicas sobre acústica, psicoacústica e calibração. In: Lopes Filho O. Tratado de fonoaudiologia. São Paulo: Tecmedd; 2004. p. 69-88. 